\title{
Task set persistence modulates word reading following resolution of picture-word interference
}

\author{
Michael E. J. Masson, Daniel N. Bub, And Yoko Ishigami \\ University of Victoria, Victoria, British Columbia, Canada
}

\begin{abstract}
We extend the finding that word reading slows following successful responses to a color-word Stroop interference task (Masson, Bub, Woodward, \& Chan, 2003). Word reading was assessed in a picture-word interference task in which subjects alternated between naming a picture (with either a word or a row of $X \mathrm{~s}$ superimposed on it) and reading a word. For the word-reading task, words were presented either in isolation or superimposed on a picture. Word reading was slower after subjects responded to a bivalent stimulus that required resolution of conflict (naming a picture with a word superimposed on it) than after they responded to a stimulus that involved no conflict (naming a picture with $X$ s superimposed on it), indicating modulation of dominant task performance. This effect was found when word-reading targets were superimposed on pictures but not when those targets were presented in isolation. Modulation of word reading, therefore, appears to be the result of interference from a persistent picturenaming task set, cued by a stimulus configuration that invites execution of both competing tasks.
\end{abstract}

Making a task-specific response to a stimulus to which there may be multiple responses requires a form of cognitive control. A classic example of this situation is the Stroop color-naming task (Stroop, 1935), in which successful naming of a color word printed in an incongruent ink color (e.g., RED printed in green) requires selective responding to the color dimension. Formal models of cognitive control explain the ability to resolve this type of task conflict as a function of enhanced activation of the intended task set (Cohen, Dunbar, \& McClelland, 1990) or suppression of the competing task set (Botvinick, Braver, Barch, Carter, \& Cohen, 2001; Cohen \& Huston, 1994; Melara \& Algom, 2003; Roelofs, 2003). These proposed control operations are consistent with empirical evidence of interference with word-reading processes that occurs when subjects switch between making color-naming and making word-reading responses to Stroop stimuli (Allport, Styles, \& Hsieh, 1994, Experiment 5). Allport et al. suggested that a form of task set inertia developed while subjects performed the color-naming task under Stroop interference. When subjects switched to word reading, the color-naming task set persisted and interfered with efficient execution of a word-reading response.

In their initial formulation of the concept of task set inertia, Allport et al. (1994) theorized that this process involved a combination of persistent facilitation of the processing pathway associated with the nondominant task (color naming) and persistent suppression of the dominant processing pathway (word reading). They also proposed that item-specific effects could contribute to task set inertia. Naming the color of a specific word-color compound was assumed to create a form of memory for that particular stimulus-response pair that would later interfere with the ability to respond to that same stimulus compound with a word-reading response, constituting a form of negative priming. This item-specific effect was shown to persist over time (see also Allport \& Wylie, 1999, 2000; Wylie \& Allport, 2000).

Experiments by Waszak, Hommel, and Allport (2003, 2004, 2005) with the picture-word interference paradigm have provided additional support for item-specific contributions to the cost of switching from a nondominant to a dominant task. In the Waszak et al. experiments, subjects alternated between picture naming and word reading in response to picture-word compounds. Negative priming was found on switch trials - that is, word-reading latency was longer when words had previously occurred as distracting stimuli in picture-naming trials than when words had not appeared in the picture-naming tasks (Waszak et al., 2005). Waszak and colleagues also demonstrated another form of item-specific interference when subjects switched to the dominant word-reading task. If the word target was paired with a picture that had been named earlier in the picture-naming task, then word reading was slowed relative to when the picture distractor had not previously been named. This interference effect was referred to as competitor priming and was attributed to priming of the irrelevant picture-naming task set caused by prior experience with a specific picture stimulus in the picturenaming task.

The emergence of strong evidence for item-specific learning produced in the course of resolving task conflict points up the importance of separating this influence from purported effects of task set activation or suppression, which are presumably independent of specific item

M. E. J. Masson, mmasson@uvic.ca 
effects. This need for separation is not trivial, particularly when small item sets (e.g., of colors) are used, leading to repeated presentation of stimulus attributes across tasks. One source of evidence for a contribution of task set suppression, independent of item-specific learning, was provided by Masson, Bub, Woodward, and Chan (2003). They required subjects to alternate between color-naming and word-reading tasks under two conditions. In the incongruent condition, color naming was performed for words printed in color, whereas word reading was performed for words printed in black (which was not one of the colors used in the color-naming tasks). In the neutral condition, color-naming stimuli were rows of asterisks instead of words, and word reading was still done with words printed in black. Color naming was, of course, slower in the incongruent condition (a basic Stroop effect), but the interesting outcome was that word reading was substantially slower in the incongruent condition. Masson et al. concluded that on incongruent trials, the dominant task of word reading was suppressed in the course of successful completion of color naming and that this suppression was revealed when subjects subsequently attempted to read a word.

This modulation of word reading differs in a number of ways from the negative and competitor priming effects reported by Waszak et al. $(2003,2004,2005)$ and Allport and Wylie (2000). First, the size of the modulation that Masson et al. (2003) found was unaffected by the sizes of the word sets used (which comprised either a large set of nonrepeating words or a small set of repeating words). With nonrepeating items, negative priming cannot make a contribution to word reading, since no item has appeared previously as a distractor in the color-naming task. Second, words presented in the reading task appeared in black, a color not used in the color-naming task. Thus, competitor priming could not have affected performance.

We therefore have evidence supporting the proposal that word reading can be slowed via a mechanism that involves reading in general, independently of possible item-specific effects associated with negative or competitor priming. The mechanism responsible for this slowing might be a form of dominant task suppression occasioned by that task's interference with performance of the nondominant color-naming task, as suggested by Allport and colleagues (Allport et al., 1994; Allport \& Wylie, 1999, 2000) and by Masson et al. (2003). The modulation of word reading reported by Masson et al. was obtained using a paradigm that involved color naming and word reading. We propose that a similar modulatory mechanism should contribute to slower word reading in other instances in which reading is the dominant task and is the source of interference in the performance of a less-practiced task. In the experiments reported here, we tested this proposal using the picture--word interference paradigm. This paradigm is of special interest because it served as the means by which Waszak et al. (2003, 2004, 2005) demonstrated the item-specific phenomena of negative and competitor priming. The present experiments were designed to determine whether general modulation of word reading occurs even when steps are taken to preclude the contribution of these two item-specific influences.

\section{EXPERIMENT 1}

Masson et al. (2003) showed that word reading slowed when words were presented in black after a color-naming response. They assumed that this arrangement qualified as presenting a univalent stimulus for word reading (since black was not one of the colors used in the color-naming task). Indeed, the same assumption was made by Gilbert and Shallice (2002) in their model of the influence of color-word Stroop interference and task switch costs. In the picture-naming paradigm, we assumed that an equivalent condition would be created by presenting word-reading targets with no background picture. Thus, in Experiment 1, subjects alternated between naming a picture with a string of letters (a word in the incongruent condition and a row of $X \mathrm{~s}$ in the neutral condition) superimposed on it and reading a word presented in isolation. By presenting word-reading targets in isolation, we prevented competitor priming from affecting word reading. To be consistent with most of the experiments reported by Masson et al., which used the color-word Stroop task, we used a small set of words. To avoid the possible influence of negative priming on word-reading performance, one set of words appeared as distractors in the incongruent condition of the picture-naming trials, and a different set of words served as targets in the word-reading trials (Waszak et al., 2003, 2004, 2005). Experiment 1 thus provided a clear test of the proposal that modulation of word reading that follows conflict resolution (in which reading is the source of unwanted conflict) is due to a process other than competitor priming or negative priming (such as suppression of the word-reading task set).

\section{Method}

Subjects. Twenty-four introductory psychology students at the University of Victoria received extra credit for their participation in Experiment 1 . Three additional subjects were tested, but their data were excluded from analysis because of unusually high error rates (over 20\% in some conditions).

Materials. Forty-eight unrelated objects were selected from the Snodgrass and Vanderwart (1980) set. Half of these were presented as grayscale drawings (Rossion \& Pourtois, 2004), and the names of the other 24 were presented as word stimuli. According to norms provided by Barry, Morrison, and Ellis (1997), the mean familiarity rating for the 24 pictured objects was 3.10 , and the mean rating for the 24 objects whose names were used was 3.38 . These ratings were based on a 5-point scale, with 5 indicating the highest level of familiarity. Displays for picture naming consisted of a grayscale drawing with an uppercase letter string superimposed on it (see Figure 1). In the neutral condition, the letter string was a row of five $X_{\mathrm{s}}$; in the incongruent condition, the letter string was an object name. Drawings of objects fit within a field whose visual angle was $10.3^{\circ} \mathrm{high} \times 11.4^{\circ}$ wide when viewed from $50 \mathrm{~cm}$. These angles varied somewhat from subject to subject and within a session, since subjects were allowed to freely position themselves in front of the monitor. Words were printed in bold Helvetica font with uppercase letters that subtended angles of $0.8^{\circ}$ vertically and a maximum of $0.7^{\circ}$ horizontally. The same font was used for presenting words in isolation during the word-reading task.

For each subject, 12 of the 24 pictures were randomly selected for presentation on picture-naming trials. The other 12 pictures were not used for that subject. In addition, an independent random assignment of words was carried out for each subject, whereby half of the 24 words were presented as distractors in the picture-naming task in the incongruent blocks, and the other half were used in the wordreading task in both incongruent and neutral blocks. 


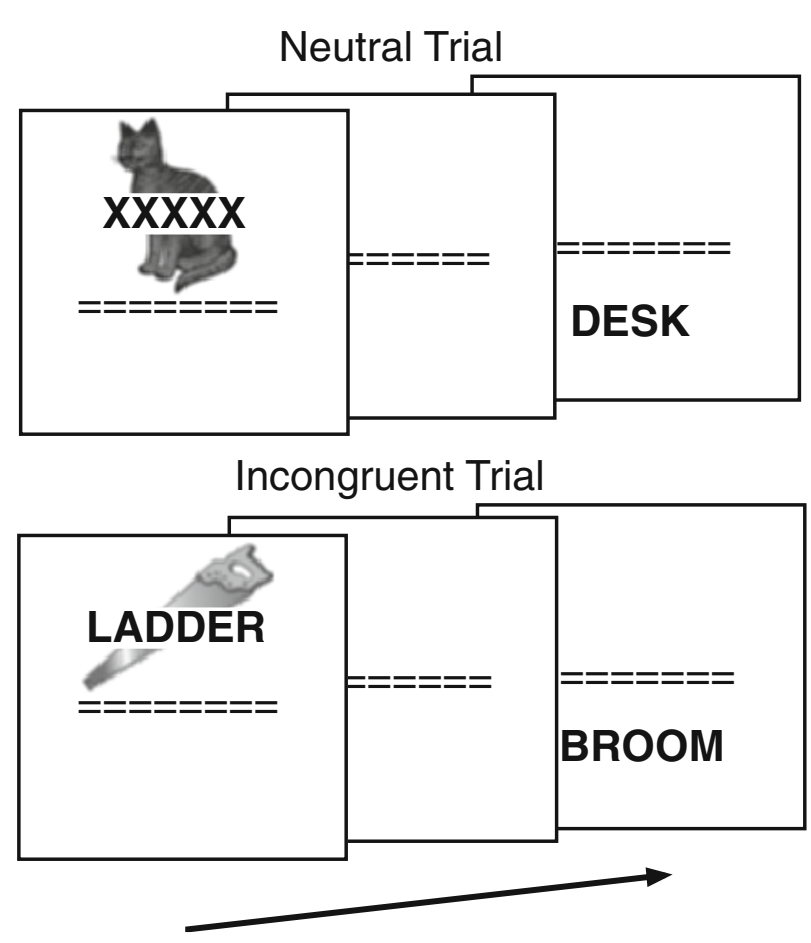

Figure 1. Example of displays for a neutral trial and an incongruent trial in Experiment 1. The arrow indicates the sequence of events over time.

Procedure. Stimuli were presented using a Macintosh G3 computer equipped with two monitors. One monitor displayed stimuli for the subject, and the other displayed target responses for the experimenter, who scored the responses online. The computer's internal microphone was used to detect vocal responses, allowing accurate recording of response latency. Subjects were informed that they would be alternating between two different tasks, picture naming and word reading. They were instructed to respond as rapidly and as accurately as possible. Each trial began with the presentation of a row of equal signs at the center of the screen. After a $495-\mathrm{msec}$ pause, a line drawing of an object with a word or a row of $X$ s superimposed on it appeared above the equal signs. The task was to say the name of the picture out loud. As soon as the subject's response was detected, the picture was erased, and, after a pause of $750 \mathrm{msec}$, a single word appeared below the equal signs. Subjects then read that word aloud. Both the equal signs and the word disappeared after that response. Figure 1 illustrates a sample sequence of displays for trials from the neutral and incongruent conditions, respectively. The experimenter made two keypresses to classify the subject's responses on the picture-naming and word-reading tasks as correct or incorrect (including false starts or partial responses). The next trial began automatically $1 \mathrm{sec}$ after the experimenter's keypresses.

A series of 16 blocks of 12 trials each was presented. Eight blocks of neutral trials and 8 blocks of incongruent trials were presented in an alternating sequence, with order of blocks (neutral first vs. incongruent first) counterbalanced across subjects. Neutral and incongruent blocks were distinguished only by the nature of the item superimposed on the pictures in the picture-naming task (a row of $X \mathrm{~s}$ in the neutral blocks and a word in the incongruent blocks). Each of 12 pictures was presented once in the picture-naming task for each block of trials, and each of the 12 words assigned to the word-reading task appeared once per block in both the incongruent and the neutral blocks. The 12 words used as distractors in the picture-naming task were presented once, superimposed on a picture, in each incongruent block and were never presented in the word-reading task. Pair- ings of pictures and words in the incongruent blocks of the picturenaming task varied randomly across blocks. The first 2 blocks were treated as practice trials, and results from these were not included in the analyses. A test session was completed in about $30 \mathrm{~min}$.

\section{Results and Discussion}

For each subject, mean correct response latencies and percentage of error were computed for the picture-naming and word-reading tasks in the neutral and incongruent blocks. Any trial outcome other than a correct response properly detected by the computer's microphone was classified as an error. Response latencies from correct trials were excluded from analysis if they were shorter than $250 \mathrm{msec}$, or if they were longer than $2,000 \mathrm{msec}$ in the picture-naming task or $1,300 \mathrm{msec}$ in the word-reading task. These response latency boundaries were established so that no more than $.5 \%$ of correct response latencies were excluded (Ulrich \& Miller, 1994). Applying these criteria resulted in the exclusion of . $3 \%$ and $.4 \%$ of correct latencies in the picture-naming and word-reading tasks, respectively. Type I error rate was set at .05 for the significance tests reported here.

Mean correct response latency and percentage error in each task are shown in Figure 2. Although there was a significant Stroop interference of $105 \mathrm{msec}$ in the picture-naming task for response latency, with longer latencies in the incongruent condition $\left[F(1,23)=157.59, M S_{\mathrm{e}}=838\right]$, there was no reliable modulation of word reading $(F<1)$. The test for an effect of neutral versus incongruent condition on word reading had a power of .80 to detect a modulation effect of merely $5 \mathrm{msec}$. For error rates, there was no significant effect of block in either the picture-naming task $[F(1,23)=$ $\left.1.72, M S_{\mathrm{e}}=3.07\right]$ or the word-naming task $(F<1)$.

There was clear evidence of interference in the picturenaming task from the presence of a competing word. For the word-reading task, however, there was no evidence of slowed or more error-prone responding in the incongruent condition. Execution of the reading task, then, was not measurably affected at all by the incongruent condition.

By presenting words in isolation on the word-reading task, we prevented competitor priming from slowing performance. Negative priming was ruled out because we used different sets of words as distractors during picture naming and as targets during word reading. Thus, any modulation of word reading could safely be ascribed to a different process, such as suppression of word reading arising from conflict resolution of picture-word interference. Surprisingly, however, no modulation was observed, indicating that word reading had not been suppressed in the course of naming pictures under conditions of conflict.

The lack of any clear modulation of word reading in Experiment 1 led us to reexamine the interpretation of wordreading modulation put forward by Masson et al. (2003). In the color-word interference paradigm used by Masson et al., slowed word reading in the interference condition was attributed to suppression of word reading. The absence of an interference effect in Experiment 1 suggests that resolving conflict generated by performing a nondominant task on a bivalent stimulus that also invites word reading is not sufficient to suppress the word-reading task set. What, 

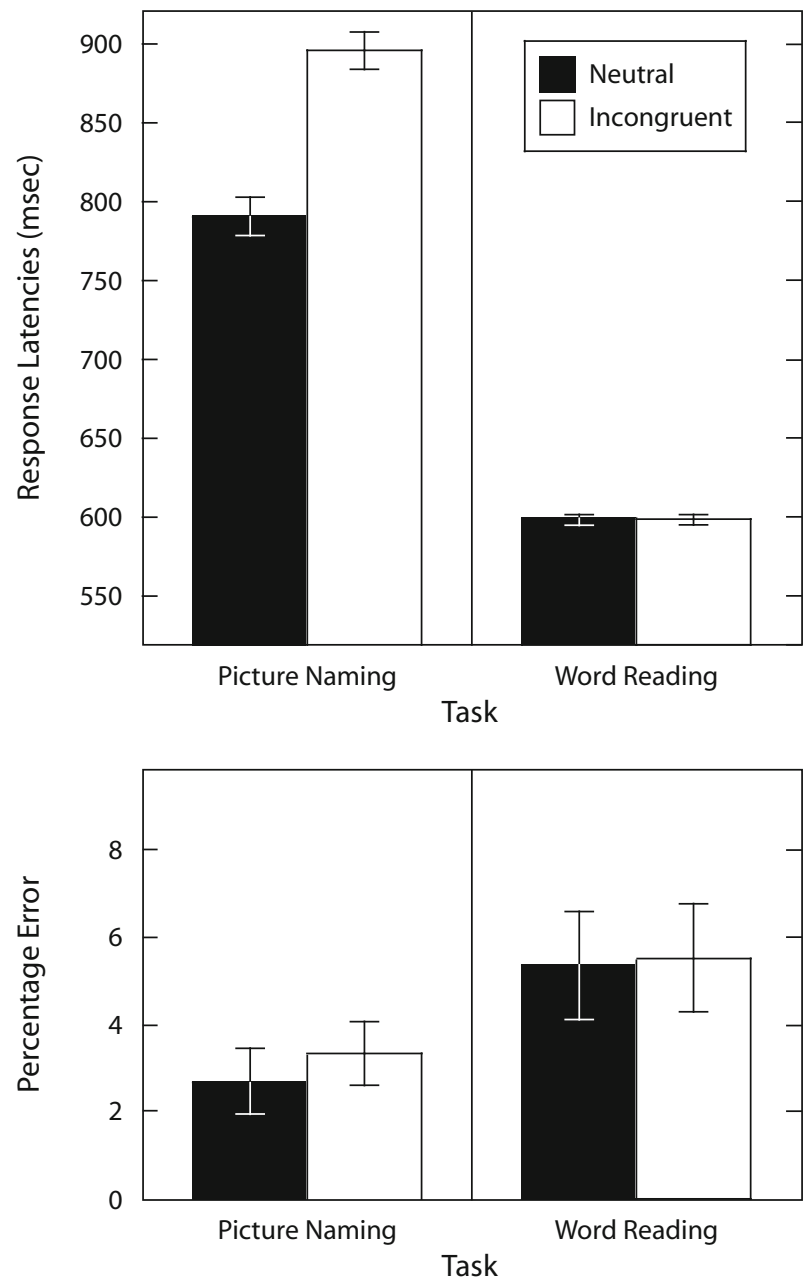

Figure 2. Mean response latencies and percentage errors in the picture-naming and word-reading tasks in Experiment 1. Error bars represent $95 \%$ within-subjects confidence intervals (Loftus \& Masson, 1994; Masson \& Loftus, 2003).

then, might have been the reason for slowed reading in the color-word paradigm? Masson et al. assumed that presenting a word in black meant that word-reading stimuli were functionally univalent and therefore did not invite performance of the color-naming task. It is possible, however, that even though black was not one of the colors used for color naming, looking at a word printed even in that color was sufficient to cue the color-naming task set. That task set may have remained active following execution of the previous color-naming response and could have been cued during the subsequent word-reading trial, creating a source of interference. This persistence of a task set is an aspect of task set inertia proposed by Allport and colleagues (Allport et al., 1994; Allport \& Wylie, 2000).

\section{EXPERIMENT 2}

The possibility that cuing of the nondominant task set is responsible for slowed word reading following execution of the nondominant task was tested in Experiment 2. Unlike the color-word paradigm, in which it may be impossible to visually present a word in a manner that would not cue the color-naming task set, the picture-word paradigm offers a way forward. With picture naming as the nondominant task, presentation of a word in isolation would be unlikely to cue that task set. The picture-naming task could be cued, however, by presenting a word-reading target superimposed on a picture, as in the Waszak et al. $(2003,2004,2005)$ experiments. Thus, Experiment 2 replicated Experiment 1, except that on half of the word-reading trials in both the neutral and incongruent blocks, words were superimposed on a picture rather than presented in isolation. Different words and pictures were used in the picture-naming and word-reading tasks to prevent negative and competitor priming from affecting word-reading performance.

This design simultaneously provided a test for suppression of the word-reading task set and for cued activation of the picture-naming task set. Suppression should lead to slowed word reading regardless of whether words are tested in isolation or with a superimposed picture. If cuing of the nondominant task set is critical, however, then slowed word reading should be seen only when words are tested with a superimposed picture.

We also examined the possibility that modulation of word reading might be due to greater stimulus uncertainty in the incongruent blocks of trials, since twice as many words appear in them (across picture-naming and word-reading tasks) as in neutral blocks. Thus, it could be claimed that the incongruent blocks generate greater uncertainty about word stimuli and that this difference could lead to slower word reading (Melara \& Algom, 2003). Therefore, an additional variant of Experiment 2 was conducted in which the number of words seen in the incongruent blocks was reduced from 24 to 12 (6 as distractors in picture-naming trials and 6 as targets in word-reading trials). Thus, in both the incongruent and neutral blocks, 12 different words were presented across the two tasks. If differential word-stimulus uncertainty is responsible for any slowed word reading that might occur in the incongruent condition, then the effect should not appear in this variant of Experiment 2.

\section{Method}

Subjects. Forty-eight new subjects, drawn from the same population as were those in Experiment 1, were tested in Experiment 2. Half of the subjects were assigned to each version of the experiment.

Materials and Procedure. The 24 pictures of objects and 24 object names used in Experiment 1 were used here. Trial blocks were arranged as in Experiment 1, with the following exceptions: In Experiment $2 \mathrm{~A}$, on a randomly selected half of the trials within each block, the word presented in the word-reading task was superimposed on a picture of an object rather than presented in isolation. The 12 pictures not presented in the picture-naming task were used for this purpose. In a block of trials, the particular words presented alone versus on a picture were randomly determined for each block so that across blocks, an individual word sometimes appeared alone and sometimes was superimposed on a picture. These picture-word pairings varied randomly. Half of the object names, randomly selected, were used as distractors in the picture-naming task, and the other half were targets in the word-reading task, as in Experiment 1.

In Experiment 2B, 6 rather than 12 randomly selected words were used as distractors for the picture-naming task in incongruent blocks of trials. Each word appeared twice within a block. An additional 6 words were randomly selected for presentation as word-reading targets in both incongruent and neutral blocks. Six other words were 
used as word-reading targets only in neutral blocks. The remaining 6 words were not presented to a particular subject. This arrangement meant that subjects were exposed to 12 different printed object names in both the neutral and the incongruent blocks - 12 word-reading targets in the neutral blocks and 6 word-reading targets and 6 distractors for the picture-naming tasks in the incongruent blocks.

Trials were run as in Experiment 1, and the first two blocks (one incongruent and one neutral) were treated as practice trials. Test sessions took about $30 \mathrm{~min}$ to complete.

\section{Results and Discussion}

Response latencies were excluded as in Experiment 1, except that the upper cutoffs were $1,900 \mathrm{msec}$ for the picturenaming task and 1,200 msec for the word-reading task in Experiment 2A, and 2,000 $\mathrm{msec}$ and 1,900 $\mathrm{msec}$, respectively, for the same tasks in Experiment 2B. These cutoffs resulted in the exclusion of between $.35 \%$ and $.48 \%$ of trials within a task in a given experiment. A preliminary ANOVA that included experiment as a factor (2A vs. 2B) found no reliable interactions involving that variable for either the picture-naming or the word-reading task. Moreover, separate analyses of the two experiments revealed the same pattern of effects for both versions of the experiment. Therefore, the data were collapsed across the two versions of Experiment 2 and are reported here as a single experiment.

The mean response latencies and percentage errors for each task are shown in Figure 3. An ANOVA indicated that there was once again a strong interference effect $(116 \mathrm{msec})$ in the picture-naming task, with longer latencies in the incongruent condition $\left[F(1,47)=410.04, M S_{\mathrm{e}}=786\right]$. This effect also emerged in the error data $[F(1,47)=31.00$, $\left.M S_{\mathrm{e}}=1.62\right]$. Word-reading data were analyzed only for words that appeared as targets in both the neutral and incongruent blocks. Data for words that appeared only in the neutral blocks were excluded (this exclusion was relevant only to data from subjects in Experiment 2B). The analysis included condition (incongruent vs. neutral) and word context (alone vs. superimposed on a picture) as repeated measures factors. Both factors had reliable effects in the analysis of response latency, with longer latencies in the incongruent than in the neutral condition [654 vs. $646 \mathrm{msec} ; F(1,47)=$ $\left.7.85, M S_{\mathrm{e}}=454\right]$ and when words appeared superimposed on pictures rather than alone [694 vs. $606 \mathrm{msec} ; F(1,47)=$ $\left.282.45, M S_{\mathrm{e}}=1,318\right]$. These two factors also produced a significant interaction $\left[F(1,47)=7.37, M S_{\mathrm{e}}=420\right]$. A simple effects analysis found reliably longer latencies for the incongruent condition when words were presented with pictures [702 vs. $\left.686 \mathrm{msec} ; F(1,47)=15.82, M S_{\mathrm{e}}=420\right]$, but no such effect when words were presented alone $(606 \mathrm{msec}$ for both conditions; $F<1$ ). The test for an incongruentneutral difference in the alone-context condition had a power of more than .99 to detect an effect equal to that found in the picture-context condition. An analysis of error data in the word-reading task revealed no significant effects.

By introducing bivalency into the word-reading task, we were able to produce a clear modulation of word reading that was not observed when words were read in isolation. That is, when word-reading targets were superimposed on pictures, they were read more slowly in the incongruent than in the neutral condition. At the same time, because nonoverlapping sets of pictures and words were used in
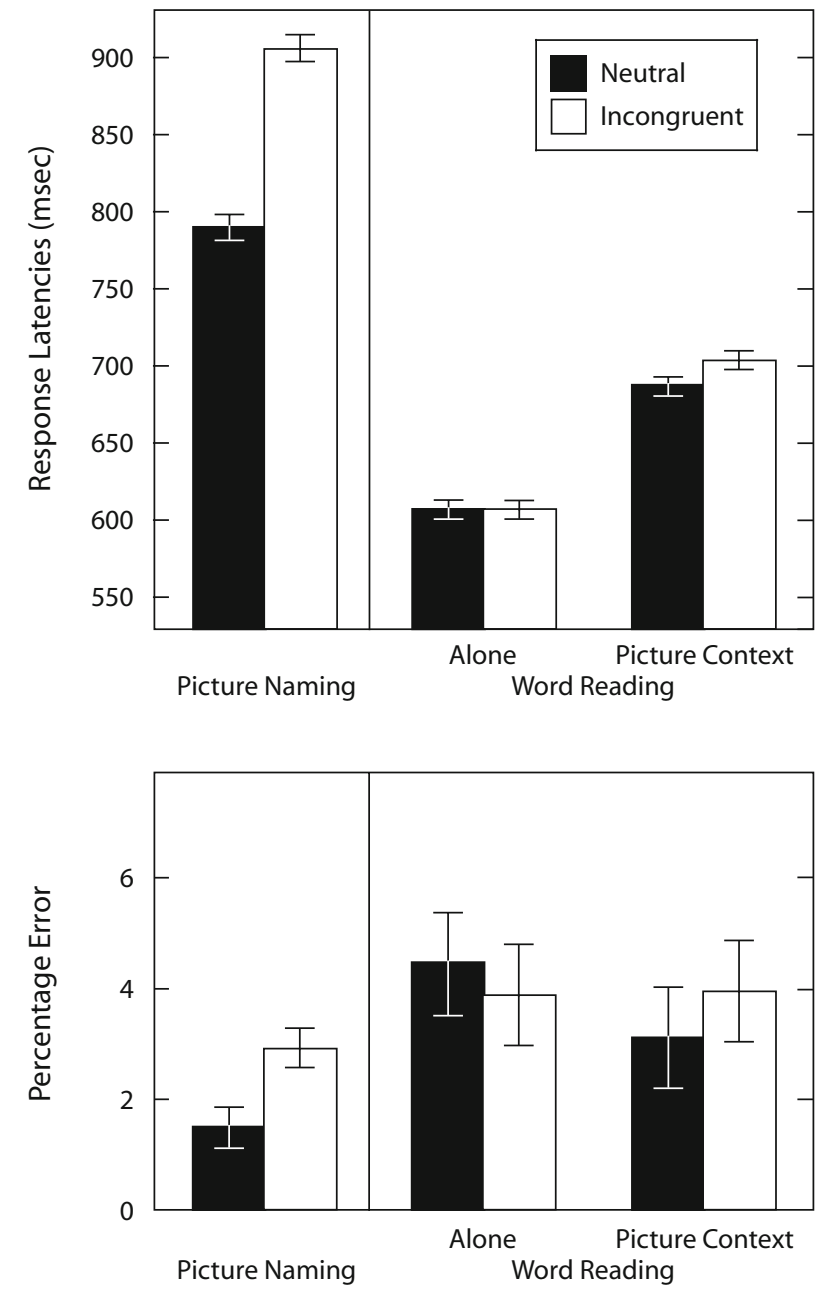

Figure 3. Mean response latencies and percentage errors in the picture-naming and word-reading tasks in Experiment 2. In the word-reading task, words appeared either alone or superimposed on a picture. Error bars represent $\mathbf{9 5 \%}$ within-subjects confidence intervals.

the picture-naming and word-reading tasks, item-specific negative priming and competitor priming could not have influenced performance during word reading. Thus, the slowing of word reading seen here is general, extending beyond items experienced in the context of resolution of the powerful picture-word interference observed during picture naming. It also appears, however, that demonstrating this modulation depends on using a bivalent stimulus during word reading. The absence of an effect of block type on reading words presented in isolation means that we again failed to obtain evidence that the word-reading task set was suppressed following completion of a nondominant task. The presence of pictures during word reading appears to have cued the picture-naming task set, which would have been particularly active in the incongruent condition, leading to interference with word reading. The similarity in the pattern of results across the two versions of Experiment 2 indicates that stimulus uncertainty in the word sets was not responsible for slower word reading in the incongruent condition. 


\section{GENERAL DISCUSSION}

We have shown that when subjects alternate between two tasks, one of which is more practiced (word reading) and conflicts with the other (picture naming), the less-practiced task set may interfere with subsequent performance of the dominant task (see also Allport et al., 1994). This interference, however, was apparent only when a bivalent stimulus invited performance of either task. Moreover, interference with word reading was not due to stimulus-specific effects of negative or competitor priming across tasks (Waszak et al., 2003, 2004, 2005), since different sets of stimuli were presented in the wordreading and picture-naming tasks. Rather, a general task effect is implied by these results.

The original concept of task set inertia, proposed by Allport and colleagues (Allport et al., 1994; Allport \& Wylie, 1999, 2000), includes two different mechanisms that might contribute to the interference effect we obtained. One possible mechanism is suppression of the word-reading task set in the course of conflict resolution during naming of a picture when a word is superimposed on the target picture. If suppression occurred and were to persist for a modest amount of time (see, e.g., Mayr, 2002; Mayr \& Keele, 2000 ), then one would expect word reading to be slowed when subjects shifted to that task following a picturenaming event that involved interference from word reading (incongruent condition). No slowing effect would be expected when picture naming did not require overcoming such interference (neutral condition). We found, however, that when subjects read words printed in isolation, reading latency was unaffected by the nature of the preceding picture-naming event. We have no evidence, then, for general suppression of the word-reading task set.

The other component of task set inertia proposed by Allport and colleagues is persistence of the nondominant (picture-naming) task set. Producing a picture-naming response under conflict involves enhanced activation of that task set, and this activation may persist for some time. If the task set is cued by a subsequent stimulus, it may become active and either produce a repetition benefit, if a picture-naming response is required again, or generate conflict with a competing task set, such as word reading. Evidence for the persistence of task set activation and its decay over time has been provided by Altmann and Gray (2002), Koch and Allport (2006), Meiran, Chorev, and Sapir (2000), and Sohn and Anderson (2001).

The effect of task set persistence that appears to be responsible for the word-reading modulation found in Experiment 2 clearly originates from task conflict. Note that our results show that the presence of a picture during word reading caused greater interference when the wordreading task was performed in the incongruent condition than when it was performed in the neutral condition. In the incongruent blocks, picture naming always involved identifying a picture when an unrelated word was printed across it, whereas in the neutral blocks, a row of $X \mathrm{~s}$ was superimposed on the pictures. In both blocks, the wordreading task was performed under a task switch, since subjects always alternated between single picture-naming and word-reading trials. Therefore, the effect we report is not a measure of switch cost. Instead, it is a reflection of the elevated task conflict that occurs during a task switch and that very likely contributes to task switch costs as they are typically measured (i.e., by a comparison between task switch and task repeat conditions using bivalent stimuli that invite execution of two conflicting tasks). In our experiments, the picture-naming task was performed on alternating trials in both the neutral and the incongruent blocks. The slowing of word reading that was seen in the incongruent blocks, then, must have been a product of the conflict between word-reading and picture-naming task sets during the picture-naming task.

An alternative to persistent task activation has an episodic flavor, somewhat like that of the negative and competitor priming mechanisms described by Waszak et al. $(2003,2004,2005)$. It is possible that when a pictureword compound is encountered during a word-reading task in an incongruent block, this compound cues memory for a recently encountered picture-word compound, even though there is no overlap in the specific stimuli that comprise these compounds. The most recent compound of this type in an incongruent block would be the one encountered in the immediately preceding picture-naming task. When subjects cue memory for that recent stimulus, the corresponding picture-naming response or task set associated with that stimulus may also be brought to mind, creating a conflict with the current word-reading task set. Differences between neutral and incongruent blocks may arise because the picture-word compound is a better cue for the preceding picture-naming trial in the incongruent condition (word superimposed on a picture) than in the neutral condition (row of $X \mathrm{~s}$ superimposed on a picture). If episodes can be cued from memory by stimulus configurations that only generally resemble previously encountered configurations, then there may be an episodic basis for the word-reading modulation we have demonstrated, just as there appears to be an episodic basis for negative and competitor priming.

Our conclusion that the modulation of word reading seen here is due to persistence of the picture-naming task set (or possibly episodic retrieval of the preceding picturenaming event) implies that a similar explanation can be applied to the word-reading modulation results reported by Masson et al. (2003). There, color-word conflict on a color-naming trial led to increased word-reading latency when subjects switched to reading a word printed in black. Masson et al. attributed this effect to suppression of wordreading processes that occurred in the course of resolving color-word conflict during the color-naming task. It now appears that a more likely explanation is that stronger persistence or enhanced cuing of the color-naming task set in the incongruent blocks slowed word reading. Even though black was not a target color in the color-naming task, the presentation of a word in black may have been encoded as a color-word compound, thereby inviting application of the irrelevant color-naming task set. Although the magnitude of the word-reading modulation seen here $(16 \mathrm{msec})$ is smaller than some of the larger effects reported by Masson et al. (40 or $50 \mathrm{msec}$ ), this difference could partly 
be due to the fact that in the Masson et al. experiments, words always appeared in only one color (black) during word reading. In the present experiments, however, wordreading targets appeared in the picture-context condition with any of 12 possible pictures, varying randomly from trial to trial. Had a single picture been used on all wordreading trials in the incongruent blocks, a larger interference effect might have been found.

\section{Conclusion}

We argue that the modulation of word reading seen here is the result of the same mechanism that produced modulation of word reading in the Masson et al. (2003) study. In both cases, modulation took the form of slowed performance of the dominant word-reading task following an episode of responding on a less-practiced task in which word reading was a source of interference. The present experiments support the conclusion that both instances of word-reading modulation are a result of a component of task set inertia envisioned by Allport and colleagues (Allport et al., 1994; Allport \& Wylie, 1999, 2000). Namely, task set activation for color or picture naming appears to persist even after a task switch and can interfere with subsequent word-reading performance if that task set is cued by the imperative stimulus. This source of interference is part of the Gilbert and Shallice (2002) model of conflict resolution and task switch cost, and it is also compatible with other, similar models of Stroop interference (see, e.g., Cohen et al., 1990; Herd, Banich, \& O’Reilly, 2006).

\section{AUTHOR NOTE}

This research was supported by discovery grants to M.E.J.M. and D.N.B. from the Natural Sciences and Engineering Research Council of Canada. We are grateful to Coco Butler, Dacia Douhaibi, Rachel Link, Meaghan Newton-Taylor, Lisa Worth, and Natalie Wuitchik for skillful assistance in conducting the experiments. Y.I. is now at Dalhousie University. Correspondence concerning this article should be addressed to M. E. J. Masson, Department of Psychology, University of Victoria, P.O. Box 3050 STN CSC, Victoria, BC, V8W 3P5 Canada (e-mail: mmasson@uvic.ca).

\section{REFERENCES}

Allport, A., Styles, E. A., \& Hsieh, S. (1994). Shifting intentional set: Exploring the dynamic control of tasks. In C. Umiltà \& M. Moscovitch (Eds.), Attention and performance XV: Conscious and nonconscious information processing (pp. 421-452). Cambridge, MA: MIT Press, Bradford Books.

Allport, A., \& Wylie, G. (1999). Task-switching: Positive and negative priming of task-set. In G. W. Humphreys, J. Duncan, \& A. [M.] Treisman (Eds.), Attention, space, and action: Studies in cognitive neuroscience (pp. 273-296). Oxford: Oxford University Press.

Allport, A., \& Wylie, G. (2000). Task-switching, stimulus-response bindings and negative priming. In S. Monsell \& J. Driver (Eds.), Control of cognitive processes: Attention and performance XVIII (pp. 35-70). Cambridge, MA: MIT Press.

Altmann, E. M., \& Gray, W. D. (2002). Forgetting to remember: The functional relationship of decay and interference. Psychological Science, 13, 27-33.

Barry, C., Morrison, C. A., \& Ellis, A. W. (1997). Naming the Snodgrass and Vanderwart pictures: Effects of age-of-acquisition, frequency, and name agreement. Quarterly Journal of Experimental Psychology, 50A, 560-585.
Botvinick, M. M., Braver, T. S., Barch, D. M., Carter, C. S., \& CoHEN, J. D. (2001). Conflict monitoring and cognitive control. Psychological Review, 108, 624-652.

Cohen, J. D., Dunbar, K., \& McClelland, J. L. (1990). On the control of automatic processes: A parallel distributed processing account of the Stroop effect. Psychological Review, 97, 332-361.

Cohen, J. D., \& Huston, T. A. (1994). Progress in the use of interactive models for understanding attention and performance. In C. Umiltà $\&$ M. Moscovitch (Eds.), Attention and performance XV: Conscious and nonconscious information processing (pp. 453-476). Cambridge, MA: MIT Press, Bradford Books.

Gilbert, S. J., \& Shallice, T. (2002). Task switching: A PDP model. Cognitive Psychology, 44, 297-337.

Herd, S. A., Banich, M. T., \& O'Reilly, R. C. (2006). Neural mechanisms of cognitive control: An integrative model of Stroop task performance and fMRI data. Journal of Cognitive Neuroscience, 18, 22-32.

Koch, I., \& Allport, A. (2006). Cue-based preparation and stimulusbased priming of tasks in task switching. Memory \& Cognition, 34, 433-444.

Loftus, G. R., \& Masson, M. E. J. (1994). Using confidence intervals in within-subject designs. Psychonomic Bulletin \& Review, 1, 476-490.

Masson, M. E. J., Bub, D. N., Woodward, T. S., \& Chan, J. C. K. (2003). Modulation of word-reading processes in task switching. Journal of Experimental Psychology: General, 132, 400-418.

Masson, M. E. J., \& Loftus, G. R. (2003). Using confidence intervals for graphically based data interpretation. Canadian Journal of Experimental Psychology, 57, 203-220.

MaYr, U. (2002). Inhibition of action rules. Psychonomic Bulletin \& Review, 9, 93-99.

Mayr, U., \& Keele, S. W. (2000). Changing internal constraints on action: The role of backward inhibition. Journal of Experimental Psychology: General, 129, 4-26.

Meiran, N., Chorev, Z., \& Sapir, A. (2000). Component processes in task switching. Cognitive Psychology, 41, 211-253.

Melara, R. D., \& Algom, D. (2003). Driven by information: A tectonic theory of Stroop effects. Psychological Review, 110, 422-471.

Roelofs, A. (2003). Goal-referenced selection of verbal action: Modeling attentional control in the Stroop task. Psychological Review, 110, 88-125.

Rossion, B., \& Pourtors, G. (2004). Revisiting Snodgrass and Vanderwart's object set: The role of surface detail in basic-level object recognition. Perception, 33, 217-236.

SnOdgrass, J. G., \& VANDERWART, M. (1980). A standardized set of 260 pictures: Norms for name agreement, image agreement, familiarity, and visual complexity. Journal of Experimental Psychology: Human Learning \& Memory, 23, 174-215.

SoHn, M.-H., \& ANDERson, J. R. (2001). Task preparation and task repetition: Two-component model of task switching. Journal of Experimental Psychology: General, 130, 764-778.

Stroop, J. R. (1935). Studies of interference in serial verbal reactions. Journal of Experimental Psychology, 18, 643-662.

UlRich, R., \& Miller, J. (1994). Effects of truncation on reaction time analysis. Journal of Experimental Psychology: General, 123, 34-80.

WaszaK, F., Hommel, B., \& Allport, A. (2003). Task-switching and long-term priming: Role of episodic stimulus-task bindings in taskshift costs. Cognitive Psychology, 46, 361-413.

WaszaK, F., Hommel, B., \& Allport, A. (2004). Semantic generalization of stimulus-task bindings. Psychonomic Bulletin \& Review, 11, 1027-1033.

WaszaK, F., Hommel, B., \& Allport, A. (2005). Interaction of task readiness and automatic retrieval in task switching: Negative priming and competitor priming. Memory \& Cognition, 33, 595-610.

WYLIE, G., \& AllPORT. A. (2000). Task switching and the measurement of "switch costs." Psychological Research, 63, 212-233.

(Manuscript received June 26, 2006; revision accepted for publication March 22, 2007.) 